\title{
Kidung Jaka Bandung
}

\author{
TATANG RUSMANA* \\ Jurusan Teater, Fakultas Seni Pertunjukan Institut Seni Indonesia Padang Panjang
}

\begin{abstract}
The Creation of Jaka Bandung Play. Jaka Bandung Play is created from a legend using Malabar Kingdom and Bandung Lake as its story backgrounds. The name of the kingdom has been changed into Datarluhur Pangulingan for the sake of the play. The story depicts the human existence of Parahyangan represented by Rahiang Jaka Bandung. The play is approached by using particular technique of directing, so called "verbal arts". Its presentation on stage relies on beauty, hyper reality, theatricality and new theater codes.
\end{abstract}

Key words: Kidung Jakabandung, Seni Pernyataan, Tradisi Baru.

\section{Pendahuluan}

Sosiokultur orang-orang Sunda-Parahiangan masa lalu dan hari ini dengan rentetan konflikkonflik di dalamnya merupakan stimulans penting penciptaan. Stimulans utama yang melandasi gagasan ini berpijak pada keberadaan sejarah mitos Kerajaan Malabar di Bandung sebelah selatan. Pijakan lain yakni keberadaan danau purba, Danau Bandung yang hari ini menjadi jantung Kota Bandung. Idiom-idiom sosiokultur orang-orang Sunda-Parahiangan menjadi penting diangkat. Cara ini sebagai upaya mengaktualkan primordialitas masyarakat Sunda-Parahiangan di tengah era global yang cenderung kehilangan jati diri. Idiom yang dimaksud baik yang bersifat tradisional ataupun kini, ditransformasi menjadi satu wujud karya seni dalam bentuk teater kekinian. Seperti juga disampikan Umar Yunus bahwa "karya seni yang baik adalah karya yang dekat dengan kehidupan masyarakatnya dan bercerita tentang kemanusiaan" (Yunus, 1985: 43).

Kehidupan masyarakat Parahiangan yakni manusia pribumi yang bertempat tinggal di dataran tinggi Parahiangan (Bandung). Silsilah Parahiangan menunjukkan makna sebagai trah ke-Rahiangan (ke-dewataan). Parahiangan atau parahyangan, memiliki kesamaan dengan parhyangan dalam istilah Bali memiliki makna Tuhan (Bandem,
2001: 7). Parahiangan disebut juga tanah tempat turunnya rahiang-rahiang (para dewa) dalam 'waktu mitos' yang diyakini orang Sunda. Apabila merujuk pada pemaknaan filosofis tentang parahiangan, kata tersebut menunjukkan bahwa orang Sunda-Parahiangan adalah trah ke-dewataan atau ke-rahiangan. Namun kandungan nilai semua itu menjadi sangat berbeda dalam realitas sebagian besar orang Sunda-Parahiangan sekarang yang tampak profan, keduniawian, individu dan jasa.

Kepentingan penciptaan seni pertunjukan ini yakni melakukan penelusuran tentang manusia Parahiangan, melalui sejarah mitos yang berkaitan dengan Kerajaan Malabar di Bandung Selatan. Sejarah mitos Kerajaan Malabar seperti yang dituliskan oleh Haryoto Kunto dalam buku Semerbak Bunga Di Bandung Raya. Dalam catatan sejarah Bandung Raya, Pustaka Rajyarajyai Bhumi Nusantara mengungkapkan pada saat Sang Purnawarman wafat pada tahun 434 Masehi, tercatat sekitar 46 kerajaan yang jadi bawahannya. Satu di antaranya adalah Kerajaan Malabar sekitar kebun Kina Arjasari Gunung Malabar. Kerajaan Malabar ini diperintah oleh Prabu Wisnubhumi, ia memiliki seorang putri bernama Dewi Ratnamanik (Kunto, 1986: 58). Keberadaan Kerajaan Malabar telah menjadi cerita bersambung Djakabandung di tangan

*Alamat Korespondensi: Institut Seni Indonesia Padang Panjang, Jln Buukokandang, Padang Panjang. Sumatera Barat. Email: tatangmacan@yahoo.co.id. 
M.A. Salmun, tokoh utama Djakabandung, seting peristiwa Kerajaan Datarluhur-Pangalingan (Malabar) dan Danau Bandung dalam waktu mitos. Keberadaan kerajaan Malabar penting disampaikan sebagai awal berkembangnya tata kehidupan masyarakat Bandung dewasa ini.

Alasan utama penciptaan, dalam rangka meluruskan isu manusia Sunda-Parahiangan yang menyebar di sebagian masyarakat. Isu yang sangat radikal itu telah menyebutkan bahwa orang SundaParahiangan keturunan Si Tumang. Sementara Si Tumang memiliki konotasi seekor anjing, pengertian ini seperti tertuang dalam Kamus Umum Bahasa Sunda (LBSS, Terate Bandung, 1985: 540). Hal di atas tadi telah membuat kegelisahan, karena sangat dimungkinkan isu itu muncul sebagai akibat dari salah baca terhadap legenda Sangkuriang yang lahir dari Dayang Sumbi dan Si Tumang. Akan tetapi terlalu naif apabila banyak orang memaknai Si Tumang itu seekor anjing.

Hal penting yang menarik dari pemikiran Salmun, tertuang dalam surat yang ditujukan pada Kostaman pengamat pewayangan Jawa Barat: "...Djakabandung, nu ngahaja disusun pikeun nandingan Sangkuriang, sangkan dongeng Sangkuriang lebah Si Tumang, te ngagambarkeun teuing urang Sunda turunan Si Tumang" (Salmun, 1969). Artinya; Djakabandung yang sengaja disusun untuk menandingi Sangkuriang, supaya cerita Sangkuriang pada keberadaan Si Tumang, tidak terlalu menggambarkan orang Sunda turunan Si Tumang. Pemaknaan kalimat $\mathrm{di}$ atas menunjukkan seolah-olah orang Sunda turunan si Tumang. Eksistensi, permasalahan dan idiom-idiom di atas itulah yang jadi daya dorong pembentuk wujud karya teater sebenarnya. Penciptaan dengan sengaja dibuat untuk mengarahkan pandangan masyarakat, bahwa manusia Parahiangan atau Bandung adalah manusia trah Rahiang dan bukan turunan si Tumang. Maka untuk menjawab kondisi ini, tema Kidung Jakabandung sengaja diangkat sebagai sebuah tandingan. Sebagai tafsir baru terhadap Djakabandung M.A. Salmun, tafsir direlasikan dengan legenda Sangkuriang Utuy.T. Sontani, yang ditulis saat revolusi berkecamuk di tanah Sunda dalam melawan kolonialisme. Latar belakang penciptaan dilandasi juga oleh sejarah mitos budaya sumber. Berpijak dari logika mitos, ada temuan hubungan mitos yang bisa relevan dengan keadaan waktu kini.

“... dalam mitos manusia akan menemukan pemikiran kaum primitif yang bersifat progresif. Kemajuan yang dicapai manusia sekarang ini berawal dari manusia primitif yang mendewakan mitos... mitos merupakan prototipe kehidupan manusia yang universal. Dengan bentuk universal manusia kini dapat menarik kesimpulan bahwa mitos dapat dijadikan pegangan untuk kehidupan zaman ini, tentu saja diperlukan interpretasi baru" (Levi-Strauss, 2001: 27)

Orientasi mitos sebenarnya lebih pada manusianya, ini tampak pada penciptaan Kidung Jakabandung dengan tokoh utamanya Rahiang Jakabandung. Rahiang Jakabandung diciptakan sebagai gambaran prototipe semangat orang Parahiangan dengan segala kekurangan dan kelebihannya. Dalam kaitan ini, Kidung Jakabandung semakin memiliki artikulasi. Penciptaan diwujudkan lebih berorientasi pada keberadaan manusianya. Maka untuk mencapai tujuan itu, teater lebih tepat dijadikan sebagai media gagasan. "... No approach has greater potential than theatre, since humanity is its subject and human beings is its primary medium" (Brockett, 1988: 16). Ungkapan tersebut menyebutkan bahwa tidak ada karya seni lain yang memiliki potensi lebih besar selain teater, karena seni ini mendudukkan kemanusiaan menjadi subjek dan umat manusia menjadi media dasarnya.

\section{Kajian Sumber Penciptaan}

Sumber penciptaan berpijak pada cerita bersambung Djakabandung karya M.A Salmun. Cerita bersambung tersebut berbicara tentang sosiokultur masyarakat Sunda-Parahiangan tempo dulu, antara kearifan dan konflik manusianya dalam sejarah mitos yang berkaitan dengan adanya Kerajaan Malabar dan Danau Bandung. Kajian sumber ini merupakan pembacaan ulang tentang kosmologi, daya-daya religi, sekaligus pembacaan mitologi manusia dan entitasnya.

“... Penulis lakon sebagai homocreator (istilah yang dipinjam dari Michael Landman) harus mampu memanfaatkan realitas sebagai sumber ilham bagi karya-karyanya. Ia selain memanfaatkan realitas, juga melakukan selektivitas ide/gagasan sekaligus 
melakukan ruminasi (pemamah biakan) ide dan gagasan yang diseleksinya, lalu melakukan kontemplasi (perenungan). Muaranya sampai menghasilkan massage (pesan) yang ditawarkan sebagai values (nilai-nilai) dibalik bentuk." (Nalan, 1998: 10).

Pijakan lain bertolak dari manusia Parahiangan yang bersifat etnis-religius. Kosmologi Sunda kaum ladang mengenal tiga pembagian dunia dalam kesetaraan (tri tangtu), yakni: Buana Nyungcung atau Dunia Atas ini, berazaskan perempuan, basah, langit, asalnya hujan; sedang Buana larang atau Dunia Bawah, berazaskan laki-laki, kering, bumi atau tanah. Apabila dua kutub ini diharmonikan akan timbul kehidupan. Pertemuan dua kutub itu adalah kehidupan, maka lahir Dunia Panca Tengah yakni dunia manusia. Dunia manusia atau kehidupan mengandung makna realitas chaos, yang terus berproses memasuki kosmos atau Buana Nyungcung tadi.

Bagi orang sunda-Parahyangan sebagai masyarakat petani ladang, pemujaan aspek pencipta terhadap Dewa Siwa, masyarakatnya lebih meyakini terhadap Dewi Uma. Inilah sebabnya, di kalangan masyarakat Sunda Dewi Uma ini disebut sebagai Sunan Ambu, ibunda keilahian (Sumardjo, 2003: 236). Buana Nyungcung (Dunia Atas) dalam alam Sunda-Parahiangan, yakni analog dengan Sunan Ambu atau ibu keilahian. Sunan kependekan dari kata susuhunan, atau yang disembah. Ibu kedewataan yang disembah, agung, penuh kuasa, kharismatik penuh cinta kasih (Caturwati, 2006: 68). Penyembahan terhadap Dewi kehidupan, telah melahirkan prosesi ritual yang disebut upacara Ronggeng, upacara persembahan terhadap Dewi Sri atau Dewi padi yang memang ritus. Prosesi ritual ini masih berkaitan dengan posisi Sunan Ambu, sebagai Dewi penciptaan di kalangan masyarakat Parahiangan. Bentuk dari prosesi ritual ini, salah satunya hadir teater rakyat yang disebut Longser sebagi media ritual.

“... Upacara ini ditransformasikan ke dalam teater rakyat yang disebut Longser. Pemain dan penonton integral dalam sebuah komunikasi pertunjukan, dengan peralatan sederhana hanya menggunakan obor di tengah arena permainan. Para pemain keluar masuk dengan menari dan dialog sebagian diucapkan dalam bentuk nyanyian" (Saini KM, 2002: 28).
Pembacaan sumber dilanjutkan dengan pelacakan masuknya modernitas di tanah Priangan, terutama pada jaman masuknya kolonialisme VOC pada tahun 1707, yang melakukan desakralisasi terhadap budaya lokal. Ditandai dengan hancurnya sosok ronggeng sebagai media upacara pertanian (agama padi), yakni pengagungan terhadap Nyi Pohaci Sang Hiang Sri di kalangan masyarakat. Berubah menjadi pola perkebunan dengan segala dampak kolonialisme (pengaruh Barat), sosok ronggeng muncul dalam perubahan yang signifikan. Fungsi dan kedudukan ronggeng menjadi alat hiburan, dan berkembang jadi pergundikan, pelacuran, perjudian, saweran, minuman, dan penghisapan candu (Caturwati, 2006: 73). Kehancuran sosok ronggeng yang shamanis, berdampak hingga hari ini dengan ditandai migrasi pertanian menuju industrialisasi global di tanah Parahiangan. Pola pikir masyarakat berubah dari sakral (surgawi) menuju profan (keduniawian), dari desa dengan harmoni alam dan partisipasi menuju peradaban kota yang konsumtif, individual, glamor dan jasa.

“... Secara antropologis perkotaan, Bandung telah berubah menjadi kota metropolitan, pelbagai indikasi perkotaan yang berubah adalah tata ruang dan tata kotanya, pembangunan fisik bangunan (dari perkantoran sampai pertokoan, bahkan perhotelan). Efek sampingnya udara segar tak lagi dapat dinikmati, daerah-daerah pinggiran telah menyimpan polusi dan limbah, pabrikpabrik dan industri lainnya telah menjadi benteng kota yang tanpa terasa mengepung kita" (Nalan, 2006: 5).

Faktor-faktor di atas bagaimanapun tidak lepas dari pengaruh modernitas bangsa-bangsa Eropa, yang jauh sebelumnya telah meninggalkan multi jejak di tanah Parahiangan. Akibat dari pembangunan fisik tersebut, hari ini realitas primordial masyarakat Parahiangan menjadi teralinasi di buminya sendiri. Sumber penciptaan ditajamkan dengan pembacaan kembali mitos Sangkuriang karya repertoar Utuy T. Sontani. Sangkuriang Utuy T. Sontani, adalah sebuah cerita yang ditulis seiring dengan zaman revolusi berkecamuk di tanah Parahiangan. Kecerdasan Utuy dalam karya Sangkuriang, terselip simbolsimbol yang diterapkan pada tokoh-tokohnya yaitu Sangkuriang, Si Tumang, Dayang Sumbi, 
dan Guriang Tujuh atau siluman. Lakon ini sarat kritik, terutama pada keberadaan tokoh si Tumang (sindiran bagi penjajah Belanda saat itu), yang kurang lebih 350 tahun menjajah Nusantara. Parahiangan atau Bandung kini, tentu menjadi salah satu daerah kolonial Belanda. Parahiangan telah lama meninggalkan multi jejak bangsa-bangsa Eropa, seperti pemaksaan, perampasan kekayaan, bahkan pemerkosaan. Guriang (pengaruh kekuatan penjajahan lainnya), dan Sangkuriang (generasi yang lahir dan keterpengaruhan kolonialisme). Pemikiran Utuy tersebut, ditarik dan bernegasi dengan sumber utama yakni Djakabandung M.A. Salmun (Salmun: dekade sastrawan "Parahiangan" dengan kekuatan tema-temanya dalam wacana "Burak Siluman"). Ruminnasi gagasan kemudian melahirkan tafsir baru terciptanya karya Kidung Jakabandung.

Sumber penciptaan yang dirujuk baik yang bersifat lisan atau tulisan dalam bentuk susunan perkata, bahwa cerita, mitos, atau pun sejarah orang-orang Parahiangan telah lama tertanam budaya simbol alegori. Konteks ini lebih pada pemaknaan perwujudan dari bahasa menjadi benda penanda. Sebagai contoh makna sunan artinya susubunan (Sunda: Yang dihormati dan disembah), kujang artinya kudu kukuh kana jangji (Sunda: Kukuh pada janji). Sehingga sebutan untuk istilah, nama dan benda memiliki kandungan makna tidak sebatas esensi.

\section{Landasan Penciptaan}

Kidung Jakabandung memiliki makna ambigu, berasal dari kata kidung bahasa Jawa bermakna nyanyian atau tembang, sedang Jakabandung berarti nama tokoh atau "aku tokoh sekaligus aku laki-laki orang Parahiangan”. Sehingga makna Kidung Jakabandung mengandung nilai sebagai Nyanyian Jakabandung. Maksud yang menjadi visi cerita Kidung Jakabandung, bisa dimaknai sebagai "aku yang sedang dalam pencarian jati diri baik secara sosial atau pun spiritual”. Bisa juga dimaknai sebagai "cerita orang-orang Parahiangan dalam pengembaraan saleh sosial dan saleh ritual". Lakon kidung Jakabandung diciptakan sebagai gambaran perjalanan orang Parahiangan dalam mempertahankan sikap budaya primordialnya. Pengembaraannya adalah dharma mengayomi kemunduran mental sosial-spiritual dan kehan- curan tatanan lingkungan manusia yang hidup dalam situs air.

Realitas Bandung tempo dulu (Parahiangan) dipandang memiliki nilai paralel dalam waktu kekinian. Hal tersebut dijadikan landasan cipta, karena nilai primordialitasnya masih relevan dengan hari ini. Penciptaan dilakukan sebagai upaya untuk melakukan kontrol sosial, kontrol kultur terhadap situasi kekinian. Upaya untuk merealisasikan gagasan ini, ideologi kekaryaan mutlak harus dimiliki sebagai sikap idealisme (Nalan, 1998: 2). Ideologi kekaryaan akan mengarahkan sikap pada kerja penciptaan. Albert Camus menyatakan bahwa dalam proses menciptakan karya seni, seorang seniman hendak menghadirkan dunia tidak sebagaimana adanya, tetapi sebagaimana yang dirasakan dan dipahaminya, dunia yang diinginkannyameskipun fenomena itu absurd. Menciptakan karya seni hakekatnya melakukan pemberontakan terhadap absurditas. Seorang pemberontak adalah seorang yang kreatif (Djelantik, 2002: 25). Demikian halnya dengan proses penciptaan Kidung Jakabandung. Seni adalah media kesaksian yang tepat untuk melakukan penyusupan, subversi, atau konfrontasi menentang ketidakjelasan (chaos) yang menghimpit di mana kita hidup.

Merunut beberapa pikiran di atas, maka landasan teori menjadi bias, yang ada hanyalah pengungkapan eksperimental. Pembiasan menemukan peluang, dengan prinsip ketidakpastian dalam pemahaman Quantum. Quantum menyebutkan bahwa realitas fundamental itu sendiri pada hakekatnya indeterminate (takterpastikan), tak ada sesuatu yang jelas dan pasti yang menjadi dasar bagi eksistensi kita seharihari yang dapat diketahui. Segala sesuatu tentang realitas adalah dan akan tetap menjadi suatu materi dari probabilitas-probabilitas (kebolehjadiankebolehjadian), sehingga apa saja dapat dilihat dari berbagai perspektif. Kita tidak akan pernah membakukan makna esensial dari suatu fenomena seni, atau realitas sosial atau budaya. Dengan demikian, karya seni bisa dipandang pada aspek fisiknya (partikelnya) yaitu sebagai suatu yang kongkret dan terukur besarannya, atau dalam derajat yang sama ia juga bisa dilihat sebagai sesuatu gelombang yang mengandung makna, pesan-pesan, dan membangkitkan asosiasi-aso- 
siasi yang mengaitkannya dengan konteksnya (Marianto, 2006: 26-32).

Penciptaan Kidung Jakabandung, diruminnasi dari berbagai perspektif untuk menjadi peristiwa teater atau realitas pentas. Tujuannya menjauhkan bentuk agar tidak terjerumus pada keseharian. Maka dari itu, komunikasi teater benar-benar akan menjadi sebuah kabar rahasia sebagaimana dirumuskan istilah sandiwara.

“ ... Teater merupakan media rahasia untuk menyuarakan kebenaran, keadilan, kemanusiaan, kesetaraan, kebebasan, kemerdekaan bahkan gagasan-gagasan baru yang bisa sangat radikal. Sifat ambiguitas dalam segala sesuatu yang disandikan, membuat teater menjadi kubu relatif aman untuk menitipkan, menyimpan dan menyelundupkan berbagai pengertian kontroversial lewat jalur non formal. Sebagai kanal-kanal rahasia, khususnya dalam masyarakat yang sedang mengalami pergolakan nilai, ide-ide teater menjadi gerakan bawah tanah yang efektif untuk melakukan subversi terhadap status quo" (Wijaya, 2004: 42).

Penciptaan teater Kidung Jakabandung berada dalam untaian simbol dari cabang seni lainnya untuk menyimpan pesan tersebut. Tema inti lakon Kidung Jakabandung, menggambarkan inisiasi, baik tokoh ataupun tempat dimana peristiwa itu dilukiskan.

Lakon dimulai dari adanya Telaga Bandung atau Danau Bandung, alih-alih jadi bencana bagi penduduk Datarluhur-Parahiangan. Jakabandung menjadi pusat ketergantungan semua harapan. Jakabandung lalu diwarisi ilmu pande besi dan ilmu sakti oleh Guriang Tugar Bantala (Guru Jakabandung, abdi raja Darmika, Guriang hukuman Dewata). Dari tangannya tercipta senjata kujang pusaka, Ia kemudian disumpah sebagai ksatria oleh Raja Darmika (Kakeknya) untuk menjalankan dharma mengelilingi Datarluhur-Parahiangan dan Danau Bandung. Tugas utama menemukan Sanghiang Tikoro, tempat tersumbatnya aliran sungai Citarum di bawah gunung. Ia dihadapkan dengan berbagai hambatan, baik yang mengancam dirinya ataupun keselamatan semua kehidupan di kawasan situs air Danau Bandung. Peristiwa ini semata-mata sebagai proses inisiasi yang dinamik ke depan untuk menemukan martabat kemanusiaan.

\section{Konsep Perancangan}

Sutradara adalah seniman dalam kedudukannya sebagai pencipta, penyaji dan ahli seni, mampu memadukan antara cipta, rasa dan karsa (Bandem, 2001: 1). Ia adalah pencipta kondisi kerja yang amat kompleks, "The director, then, is the crucial person who stands between the theatre's potential and the audience's enjoyment; the director is the person who is most responsible for realizing that potential (Cameron, 1989: 155). Ungkapan Cameron di atas dimaksudkan bahwa, keberadaan sutradara kemudian menjadi orang yang sangat penting, kedudukannya berada di antara unsur utama penciptaan teater dan di antara masyarakat penonton; Sutradara adalah orang sangat tanggap terhadap realitas keseharian, sehingga hampir semua tahapan kerja artistik menjadi tanggungjawabnya. Kompleksitas ini merupakan konsekuensi logis dari teater sebagai seni tampilan yang multigagas.

Lakon Kidung Jakabandung disampaikan dengan cara representasi, pemanggungan tidak harus terjerumus pada keseharian yang apa adanya. Representasi akan menghadirkan panggung sebagai interpretasi seluruh formula artistik. "Representasi merupakan keinginan seniman untuk menghadirkan panggung sebagai interpretasi seluruh formula dan unsur-unsur pemanggungan yang secara kesejarahan telah hadir" (Yudiaryani, 2002:359). Namun demikian, Kidung Jakabandung tetap saya sampaikan dalam bahasa ucap seni pernyataan. Representasi lebih cenderung pada stilisasi, pengolahan, penggayaan sebagai pengkayaan, untuk menumbuhkan kreativitas warna dan garis lain dari realita keseharian. Sehingga tumbuh kebaruan bentuk seni tampilan yang tidak sebatas penyajian biasa. Konsep perancangan dalam teater adalah kerja penyutradaraan. Kerja penyutradaraan yang paling utama, yakni mengemas lakon ke atas perwujudan pentas dengan sebaik mungkin menjadi pertunjukan yang bernas, dengan menurunkan kelemahan-kelemahan sumberdaya pendukung artistik. 


\section{Penokohan Kidung Jakabandung}

Kidung Jakabandung, tafsir baru dari cerita Djakabandung. Tafsir bernegasi dengan struktur alur Sangkuriang. Terutama dalam peristiwa Sanghiang Tikoro, sebab alur cerita pada Djakabandung saat membuka Sanghiang Tikoro tidak ditemukan konflik, konflik justru ditemukan sebelum memasuki alur peristiwa Sanghiang Tikoro, itu pun berupa sub konflik. Sementara pertahanan Sanghiang Tikoro adalah Guriang Tujuh, yakni aksi mental nafsiah Sangkuriang sendiri. Keberadaan Guriang Tujuh yang dimiliki alur cerita Sangkuriang, menyebrang pada peristiwa Djakabandung dan membuat kubu menjadi oposisi antagonis. Peristiwa ini berlaku bagi Jakabandung ketika membuka Sanghiang Tikoro. Maka Jakabandung berhadapan dengan Guriang Tujuh yang dapat diartikan sebagai aksi mental dirinya.

Guriang Tujuh bisa dimaknai sebagai tahapan unsur nafsiah. Digambarkan ketika Guriang Tujuh tak mampu melawan Jakabandung dalam perang fisik, para Guriang itu merubah strategi serangan dengan cara menghilang. Kemudian Jakabandung pada saat konflik, dilukiskan perang melawan kekosongan atau perang dengan dirinya sendiri. Dalam falsafah masyarakat Sunda dikenal kosong isi atau isi kosong. Frase ini memiliki makna, Jakabandung perang dengan dirinya, atau memiliki makna tokoh menemukan dirinya (inisiasi tokoh).

Kidung Jakabandung direlasikan dengan legenda Danau Bandung, kehancuran ekologi, dan perubahan serta penamaan tempat-tempat sekitarnya. Perubahan dan penamaan ini dapat dikatagorikan ke dalam mitos asal-usul

“... menceritakan asal mula segala sesuatu, asal mula manusia, binatang, tumbuh-tumbuhan, benda-benda, pulau-pulau, tempattempat suci, institusi-institusi, ... mitos ini mengisahkan bagaimana suatu realitas itu muncul dan bereksistensi; bagaimana kosmos mula-mula dibentuk, bagaimana asal mula adanya takdir kematian bagi manusia, bagaimana manusia mempunyai jenis seks tertentu, harus hidup dalam masyarakat dengan tata tertib dan norma-norma tertentu, harus bekerja mencari nafkah untuk hidupnya" (Susanto, 1987: 76)
Dahulu Bandung adalah sebuah danau besar (Situ Hiang), sepanjang kira-kira $60 \mathrm{Km}$ dari arah timur ke barat, dan lebar 15-30 Km dari utara ke selatan. Ketinggian air danau mencapai kira-kira 725 meter dari permukaan laut, dari ketinggian permukaan air danau itulah menjadi bagian sisi telagayangumumnya dihunisebagai tempat tinggal masyarakat Bandung dahulu (Atmamihardja, 1958: 33). Mitos Danau Bandung, dapat dibaca sebagai pedoman tatanan hidup yang bisa paralel hingga kini pada mayarakatnya. Mitos atau legenda di tanah Parahiangan dipandang oleh sebagian besar masyarakat sebagai sejarah kudus, tapi ada sebagian yang memandangnya cenderung menjadi legenda atau dongengan. Eliade berpendapat, mitologi manusia arkhais itu sedikit demi sedikit mengalami desakralisasi, ini terjadi karena pengaruh-pengaruh pemikiran yang rasionalistis (Susanto, 1987: 74). Pemahaman tentang mitos, hampir selaras apa yang diungkapkan van Peursen "mitos ialah sebuah ceritera yang memberikan pedoman dan arah tertentu kepada sekelompok orang ... mitos itu memberikan arah kepada kelakuan manusia, dan merupakan semacam pedoman untuk kebijaksanaan manusia" (Peursen, 1988: 37).

M.A. Salmun memberi ilustrasi kira-kira di jaman 2000 tahun sebelum Masehi. Gunung Burangrang meletus, sebagian besar lahar mengalir ke arah selatan-barat. Namun tertahan oleh gunung di tempat yang sekarang disebut Sanghiang Tikoro, arah selatan-barat dari daerah Rajamandala (Bandung Barat). Pada tempat itulah lahar menutup aliran sungai Citarum, yang lamake lamaan membentuk telaga. Dengan ketinggian air mencapai 725 meter dari permukaan laut di pinggiran telaga. Menurut para ahli sejarah dan antropolog yang pernah melakukan penelitian Telaga Bandung, kehidupan saat itu dikategorikan pada kehidupan jaman batu, sisa-sisa jaman microlyth (Salmun, 1969: 1).

\section{Djakabandung}

Kerajaan Datarluhur Pangalingan di bawah kekuasaan Raja Darmika yang beristri Nyi Badra (Kili Suci), turunan Rahiang Genta dari BatukarutBanjaran (pinggiran Telaga Bandung arah selatan). Rahiang Genta dan Nyi Badra adalah turunan Sang Gangga (Dewa penguasa Sungai), Raja 
Darmika turunan Sang Argapati (Dewa penguasa Gunung). Sebelumnya, telah terjadi perang antara Sang Gangga dan Sang Argapati. Kemarahan Argapati lalu meletus-letuskan gunung, terutama gunung purba Burangrang di sebelah utara Danau Bandung (tepatnya di gunung Tangkuban Perahu).

Lahar Burangrang telah menyumbat Citarum di Sanghiang Tikoro, tempat mengalir sungai Citarum ke bawah gunung sebelah barat Danau Bandung. Pada kejadian itu, daratan Parahiangan berubah menjadi telaga yang disebut Danau Bandung. Danau yang besar bagi keturunan Sang Gangga telah jadi bencana. Turunan Sang Gangga memilih jalan bertapa, agar pertempuran Gangga versus Argapati sekaligus bencana itu cepat berakhir. Pertapaan mereka disetujui Sunan Ambu, sebab perkawinan Nyi Badra dengan Raja Darmika telah memberi jalan berakhirnya permusuhan. Restu Sunan Ambu, ditandai dengan turun syarat harus memiliki keturunan anak lakilaki dan diberi nama Jakabandung. Nanti lakilaki inilah yang sanggup membuka tersumbatnya Sanghiang Tikoro.

Perjalanan Jakabandung dalam membuka Sanghiang Tikoro dihadapkan dengan berbagai hambatan. Hambatan demi hambatan itu ia lewati, dengan bekal Kujang Ki Anggara (Sunda: nama bintang Mars; nama hari Selasa; nama arah Selatan) dan ilmu yang diwariskan Guriang Tugar Bantala yakni Panca Wikrama (dalam bahasa Sunda mempunyai arti permainan atau aturan lima langkah; seni bela diri Pencak Silat). Hambatan itu yakni, pertempuran dengan tiga perempuan jejadian (demit) di hutan, pertempuran dengan maung (Harimau liar) di hutan Banjaran, menutup pusaran air di tengah Danau Bandung dengan tiga anak gunung, menolong Rahiang Anjun dari amukan Badak, dan menyembuhkan penyakit kutukan yang menimpa Arcamanik (Putri Raja Palered) seorang tukang perahu wanita di Danau Bandung. Setelah memperistri Arcamanik, Ia membuka Sanghiang Tikoro tempat terbendungnya aliran sungai Citarum. Danau Bandung dikembalikan pada daratan semula, dan pada akhir cerita ia menjadi raja di Datarluhur Pangalingan menggantikan Raja Darmika kakeknya sendiri.

\section{Sangkuriang}

Sangkuriang Utuy T. Sontani. Lakon ini memiliki konflik yang berujung tragis. Pemuda Sangkuriang sebagai manusia biasa menyadari bahwa setiap manusia lahir ke dunia punya ibu dan bapak. Setelah melewati waktu yang panjang mempertanyakan keberadaan bapak pada Dayang Sumbi (ibu), ia mendapatkan jawaban bahwa bapaknya adalah si Tumang (seorang budak bungkuk pincang). Sangkuriang tidak terima atas keberadaan si Tumang, yang jauh dari bayangan yang dibayangkan dirinya. Ketidaksukaannya terhadap si Tumang mendapat sokongan dari para Guriang. Ia bunuh si Tumang dan di kemudian hari mengajukan pinangan pada Dayang Sumbi (ibu kandungnya). Dayang Sumbi menolak dengan siasat, memberikan tanjakan (hambatan) agar pinangan itu gagal. Dayang Sumbi bisa menerima pinangan itu asal dibuatkan telaga dan perahu untuk berlayar di atasnya.

Hambatan dari Dayang Sumbi inilah berkaitan dengan terbentuknya Danau Bandung, akibat dibendung aliran sungai Citarum di Sanghiang Tikoro oleh Sangkuriang dengan bantuan Guriang Tujuh. Berkaitan juga dengan Gunung Tangkuban Perahu, yakni sebuah gunung yang mirip perahu terbalik. Perahu tersebut dalam legenda Sangkuriang, adalah perahu yang dibuat Sangkuriang sebagai syarat pinangan terhadap Dayang Sumbi untuk digunakan berbulan madu melayari Danau Bandung. Namun Sangkuriang murka karena digagalkan Dayang Sumbi. Kemarahannya tumpah dengan menendang perahu. Gunung tersebut dipercaya sebagai perahu terbalik yang ditendang Sangkuriang dalam sejarah mitos masyarakat Parahiangan. Peristiwa terjadi sebagai akibat ditolaknya rencana pernikahan oleh Dayang Sumbi. Akhirnya Dayang Sumbi dikejar-kejar Sangkuriang, Dayang Sumbi lalu menikam dirinya dengan Kujang dan mencebur ke dalam Danau Bandung. Sangkuriang mengejar dan menikam dirinya dengan Kujang, ia pun mencebur ke dalam danau mengejar Dayang Sumbi.

Cerita Sangkuriang pada pembentukan cerita Sanghiang Tikoro versi Utuy T. Sontani dapat dirunut seperti ini: Sangkuriang dikuasai Guriang Tujuh dan ia masuk pada tingkat 
harmonis antara Guriang Tujuh dengan jiwanya. Tingkat harmonis itu ia nyatakan langsung, ketika berhadapan dengan Dayang Sumbi dengan segala kecantikannya. Akibatnya Sangkuriang dikuasai nafsunya sendiri dalam hal ini ditandai dengan adanya "Si Tumang" dan "Guriang Tujuh", sehingga dapat ditemukan makna simbol yang digunakan Utuy dalam penempatan sebutan, nama tokoh, dan identifikasi tempat sebagai simbol yang diarahkan pada kebutuhan zamannya ketika lakon itu dibuat. Maka sangat jelas bahwa Sangkuriang versi ini sebagai sebuah sindiran yang dialamatkan langsung pada saat Orangorang Sunda (Parahiangan) dijajah, diinjak-injak, bahkan diperkosa dan dikuasai bangsa Eropa (Belanda). Si Tumang yang jadi suami dari Dayang Sumbi, identik dengan penguasaan penjajah yang kurang lebih selama 350 tahun meninggalkan multijejak. Guriang tujuh identik dengan paham bangsa asing lainnya atau pengaruh luar yang mendarah pada diri Sangkuriang. Sementara Sangkuriang sendiri identik dengan orang Sunda yang lahir di masa penjajahan atau revolusi untuk kemerdekaan diri dan tanah kelahirannya. Maka Sangkuriang melakukan pemberontakan sporadis sampai ia bunuh diri, baik pada paham jajahan yang melekat dengan dirinya (pengaruh Guriang), atau penjajah itu sendiri yang melakukan penguasaan (identifikasi si Tumang) terhadap tempat dimana ia hidup dan berdiri (identifikasi Dayang Sumbi).

\section{Tahapan Eksplorasi}

Tahapan eksplorasi dibentuk, yakni dalam rangka pencarian model artistik utama. Model ini yakni mengadopsi budaya sumber SundaParahiangan. Aspek yang dilakukan terutama eksperimentasi untuk mencari kemungkinankemungkinan baru. Suyatna menyatakan bahwa Sutradara sebagai seniman penafsir harus mampu menemukan kemungkinan-kemungkinan baru (Anirun, 2002: 25). Eksplorasi dilakukan dalam beberapa tahapan, terutama yang berhubungan dengan proses penciptaan; diawali dari tahapan pembacaan naskah, pemilihan casting bagi peranan tokoh, hingga masuk pada proses kerja teater sebenarnya. Lakon Kidung Jakabandung sebelumnya telah diuji cobakan dalam bentuk laboratorium naskah. Kegiatan ini masih dalam bentuk eksplorasi, yakni berupa dramatik reading hingga ditampilkan dalam kenyataan pentas. Kerja ini menurut Pavis yakni termasuk pada katagori pencarian model artistik yang dieksplorasi dari tahapan artistic modeling systems, hingga perspective of the adapters yang membentuk mise en scene (Pavis, 1992: 189). Eksplorasi menjadi penting pada tatanan penyutradaraan dalam rangka menguji naskah lakon menjadi kenyataan pentas. Terutama mengolah sumberdaya aktor sebagai medium utama pertunjukan dari sisi kelebihan dan kelemahannya.

\section{Proses Penciptaan/Perwujudan Karya}

Perwujudan karya adalah tercapainya peristiwa pertunjukan di atas pentas, dan disaksikan oleh penonton audience (spectator). Dalam rangka mencapai sublimasi penampilannya, penciptaan menggunakan teknik penyutradaraan representasi. Representasi adalah pengemasan pertunjukan secara artistik merupakan kerja stilisasi, rekayasa, perusakan, sekaligus penajaman struktur dramatik atau bagian plot lakon yang meliputi ; prologis, konflik, krisis, dan resolusi. Perwujudan karya teater berkaitan dengan visi sutradara, visi sebagai suatu cita-cita atau ambisi yang ingin dicapai dari rancangan pemanggungan lakon. Visi penciptaan dibuktikan melalui pembauran formulasi teori, rekonstruksi, penciptaan estetika baru, dan ekspresi eksperimental. Upaya transformasi budaya, diharapkan bisa menjadi penyampai pesan alat kontrol sosial atau lebih jauh bicara tentang pandangan hidup.

"... Art ultimately must be valued because of its capacity to improve the quality of live-by increasing our sensitivity to others and our surroundings, by sharpening our perceptions, by reshaping our values so that moral and social concerns take precedence over materialistic goals" (Brockett, 1988: 16).

(Seni pada dasarnya harus memiliki nilai karena kemampuannya untuk memperbaiki kualitas kehidupan-memperkaya kepekaan kita terhadap orang lain dan lingkungan kita, mempertajam pengamatan kita, mengasah nilai moral dan kepedulian sosial yang harus didahulukan daripada tujuan materialistik). 
Tujuan seni yang utama adalah memanusiakan manusia, menghidupkan gairah kehidupan manusia dan masyarakat, sampai tercapainya kemajuan sosial untuk pencerahan. Maka dari itu seni harus memiliki nilai karena kemampuannya untuk memperbaiki kualitas kehidupan. Seni dapat memperkaya kepekaan kita terhadap orang lain dari lingkungan kita, mempertajam pengamatan kita, mengasah nilai moral dan kepedulian sosial.

\section{Tahapan Evaluasi}

Evaluasi dilakukan dalam rangka menyeleksi pencapaian artistik proses kerja penciptaan. Dilakukan untuk mengukur jalannya seluruh persiapan produksi dari berbagai unsur penunjang pertunjukan. Sutradara dalam kerja ini menjadi orang yang menjadi hyper actif terhadap segala unsur-unsur model artistik yang menjadi taruhan dari budaya sumber. Hal tersebut menyangkut komunikasi gagasan artistik dengan budaya target atau penonton. Naskah lakon sebagai karya sastra bagaimanapun ia belum menjadi perwujudan teater dan baru sebatas bahan bacaan (teks play). Sehingga dalam pelatihan sebagai wilayah praktis, kelemahan alur cerita harus ditemukan, bila mungkin dilakukan pengeditan adegan dan penghilangan tokoh. Tujuannya untuk memadatkan suasana dan pergerakan alur cerita (bagian-bagian plot). Evaluasi unsur cerita dari adegan ke adegan ini, berpegang pada prinsip penyutradaraan yang hakekatnya penyajian unsurunsur pertunjukan yang kuat baik isi ataupun bentuk. Sutradara harus berani menyikapi bagianbagian yang lemah yang harus ditutupi dan menghadirkan bagiannya yang kuat yang harus ditampilkan baik yang tampak ataupun tidak tampak. Sehingga teater akan lebih tampak sebagai seni tampilan yang matang disajikan, siap untuk ditonton, dinikmati, didengar bahkan dirasakan sebagai sebuah karya seni yang estetik.

\section{Penutup}

Kerja penciptaan Kidung Jakabandung sebagai seni pertunjukan (teater), merupakan sebuah rasionalisasi dari transformasi budaya sumber ke budaya target. Motivasi dasarnya yakni representasi budaya Sunda-Parahiangan lampau ditampilkan dalam kondisi kekinian. Tujuan penciptaan guna memberikan arah eksistensi, mengaktualkan primordialitas masyarakat Sunda-Parahiangan di tengah era global yang cenderung kehilangan jati diri. Sehingga proses kerja penciptaan, banyak membongkar nilai-nilai kelokalan sebagai mediasi karya. Nilai-nilai dimaksud baik yang bersifat tradisional ataupun kini, ditransformasi menjadi satu wujud karya seni pertunjukan dalam bentuk teater kekinian. Permasalahan idiom-idiom Sunda Parahiangan atau Bandung tempo dulu menjadi sarat dijadikan bahasa artistik di atas pentas. Penciptaan karya Kidung Jakabandung dengan sengaja dibuat untuk mengarahkan pandangan masyarakat bahwa manusia Parahiangan atau Bandung adalah manusia trah Rahiang (kedewataan) dan bukan turunan si Tumang. Pikiran ini disusun untuk menandingi Sangkuriang, supaya cerita Sangkuriang pada keberadaan Si Tumang, tidak terlalu menggambarkan orang Sunda turunan Si Tumang.

Karya yang lahir ini berupa curahan imajinasi penulis tentang gambaran sosiokultur masyarakat Sunda-Parahiangan hari ini yang sedang mengalami pergolakan nilai-nilai. Proses penciptaan terinspirasi oleh adanya Danau Bandung yang menjadi jantung kota Bandung sekarang. Tujuan penting penciptaan teater yakni, melakukan pernyataan tentang manusia Parahiangan, melalui sejarah mitos yang berkaitan dengan Kerajaan Malabar di Bandung selatan. Seperti yang disampaikan Haryoto Kunto: di dalam catatan sejarah Bandung Raya, Pustaka Rajyarajya i Bhumi Nusantara mengungkapkan pada saat Sang Purnawarman wafat pada tahun 434 Masehi, tercatat sekitar 46 kerajaan yang jadi bawahannya. Satu di antaranya adalah Kerajaan Malabar sekitar kebun Kina Arjasari Gunung Malabar. Kerajaan Malabar ini diperintah oleh Prabu Wisnubhumi sebagai cikal bakal orangorang Bandung hari ini.

Dasar pijak yang lain yakni pembacaan sumber masuknya modernitas di tanah Priangan, terutama pada jaman masuknya kolonialisme VOC pada tahun 1707, yang melakukan desakralisasi terhadap budaya lokal. Ditandai dengan hancurnya sosok ronggeng sebagai media upacara pertanian (agama padi), yakni pengagungan terhadap Nyi Pohaci Sang Hiang Sri di kalangan masyarakat, berubah menjadi pola perkebunan dengan segala dampak kolonialisme (pengaruh Barat). Sosok ronggeng muncul dalam perubahan yang signifikan. Fungsi dan kedudukan ronggeng menjadi alat hiburan 
dan berkembang jadi pergundikan, pelacuran, perjudian, saweran, minuman, dan penghisapan candu.

Kidung Jakabandung, merupakan penggalian tema lokal. Realitas Bandung tempo dulu (Parahiangan) dipandang memiliki nilai paralel dalam waktu kekinian. Hal tersebut dijadikan landasan cipta, karena nilai primordialitasnya masih relevan dengan hari ini. Beberapa pijakan di atas, akhirnya melahirkan bentuk drama kolosal dengan gaya penulisan puitika pantun, gaya drama klasik-kontemporer dengan idiom SundaParahiangan. Proses kerja penciptaan merujuk pada pikiran yang oleh Putu Wijaya disebut tradisi baru. Tradisi baru dalam teater ia memiliki makna tersendiri, bukan teater tradisional dan bukan pula teater Barat. Tradisi baru yakni wilayah yang menyimpan berbagai rekaman persetubuhan antara seni pertunjukan tradisi dan modern. Tradisi baru adalah pertemuan kembali teater dengan ragam teater yang tersebar, baik itu sandiwara dan lain sebagainya, ketika keduanya bersatu maka lahirlah karya-karya eksperimental maupun karya monumental.

\section{Kepustakaan}

Anirun, Suyatna. 2002. Menjadi Sutradara, Bandung: STSI Press.

Atmamihardja, R.Ma'mun. 1958. Sadjarah Sunda, Bandung-Djakarta: Ganaco N.V.

Bandem, I Made. 2001. "Metodologi Penciptaan Seni” (Kumpulan Bahan Mata Kuliah), Program Pascasarjana ISI Yogyakarta, Yogyakarta.

Brockett, Oscar G. 1988. The Essential Theatre, Fourth Edition, USA: Holt, Rinehart and Winston, Inc.
Cameron, Kenneth M. 1989. The Enjoyment Of Theatre, New York: Macmillan Publishing Company

Caturwati, Endang. 2006. "Sunan Ambu, Dewi Sri, dan Ronggeng", dalam Panggung Jurnal Seni STSI Bandung, No.XXXVIII.

Djelantik, A.A.M. 2002. Estetika Sebuah Pengantar, Bandung: MSPI dan kuBuku.

KM, Saini. 2002. Kaleidoskop Teater Indonesia, Bandung: STSI Press.

Kunto, Haryoto. 1985. Wajah Bandoeng Tempo Doeloe, Bandung: PT Granesia

Levi-Strauss, Claude. 2001. Mitos Dukun dan Sihir, diterjemahkan Agus Cremers dan De Santo Johanes. Yogyakarta: Kanisius.

Marianto, M. Dwi. 2004. Teori Quantum, Yogyakarta: Lembaga Penelitian ISI Yogyakarta.

Nalan, Arthur S. 1998. Mencipta Teater, Sebuah Pengantar Memahami Teater dan Antalogi Naskah Lakon, Bandung: CV. Geger Sunten. 2006. Teater Egaliter, Bandung: Sunan Ambu Press.

Pavis, Patrice. 1992. Theatre At The Crossroads Of Culture, Translated by Loren London and New York: Kruger.

Salmun, M.A. 1969. Kumpulan Ceritera Bersambung Djakabandung, Arsip Pribadi, Bogor: Sipatahoenan.

Sumardjo, Jakob. 2003. Simbol-Simbol Artefak Budaya Sunda, Bandung: STSI Press.

Susanto, P.S.Hary. 1987. Mitos Menurut Pemikiran Mircea Eliade, Yogyakarta: Kanisius.

Yunus, Umar. 1985 Resepsi Sastra: Sebuah Pengantar, Jakarta: PT Gramedia. 